\title{
A 52-year-old man with palpable nodule in the right breast (2010: 10a)
}

(C) European Society of Radiology 2010

\section{Case report}

A 52-year-old man consulted a doctor with a 2 month history of a lump in the right breast. The patient had no surgery or previous trauma in the area.

On physical examination he presented with a palpable nodule of $2-3 \mathrm{~cm}$ in the upper-internal quadrant, that was hard, adhering to deep structures, painless with no retraction and no abnormal axillary findings. The left breast was normal.

The mammographic study was performed with craniocaudal (CC) (Fig. 1) and mediolateral-oblique (MLO) views (Fig. 2); ultrasound was also carried out (Fig. 3)

What is the diagnosis?

Readers are invited to supply one possible diagnosis via electronic means to: robert.hermans@uzleuven.be. The subject of the email should include 'Interpretation Corner' and the number given above (e.g. Interpretation Corner 2010. 10a).

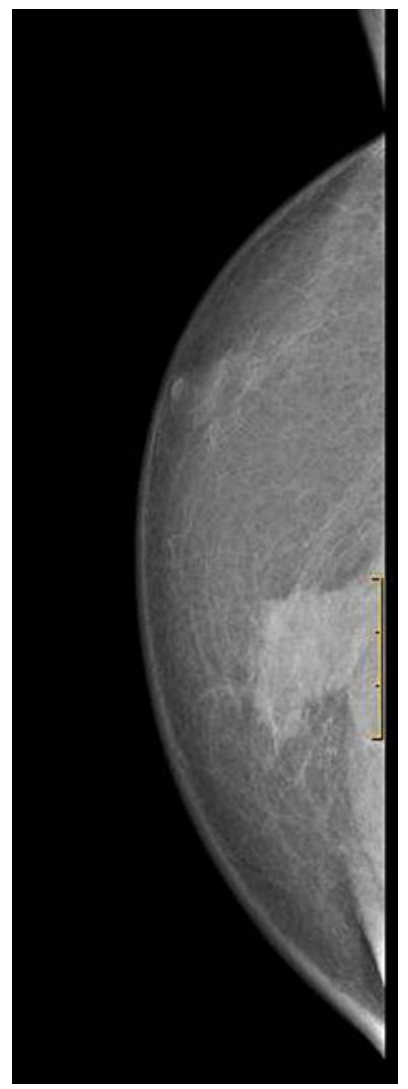

Fig. 1 Cranio-caudal mammography of the right breast
They should include their name, title, address, FAX and phone number. Deadline: one clear calendar month from distribution date. The names of the first 25 radiologists submitting the correct diagnosis will be published (only one from any individual centre and none from the host institution!).

Three months after the initial publication of the case history, the authors will publish the final diagnosis.

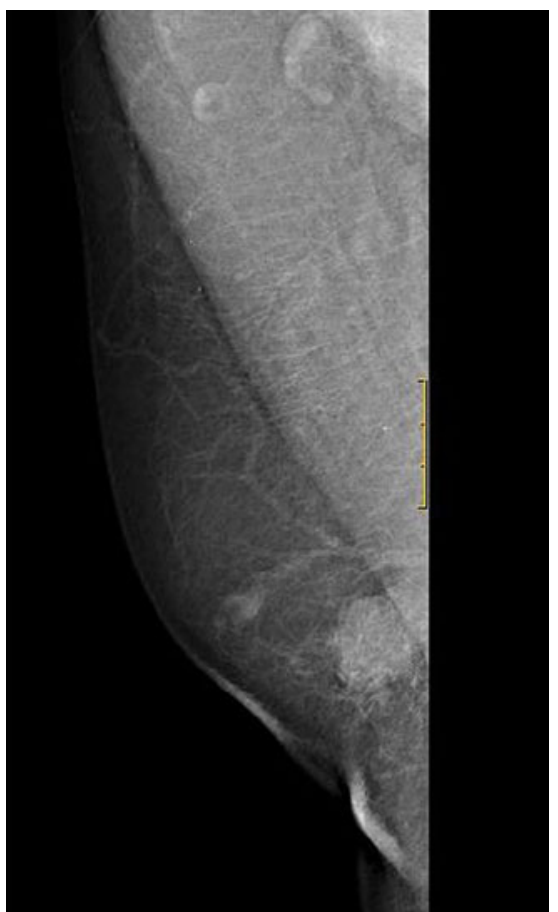

Fig. 2 Mediolateral-oblique mammography of the right breast

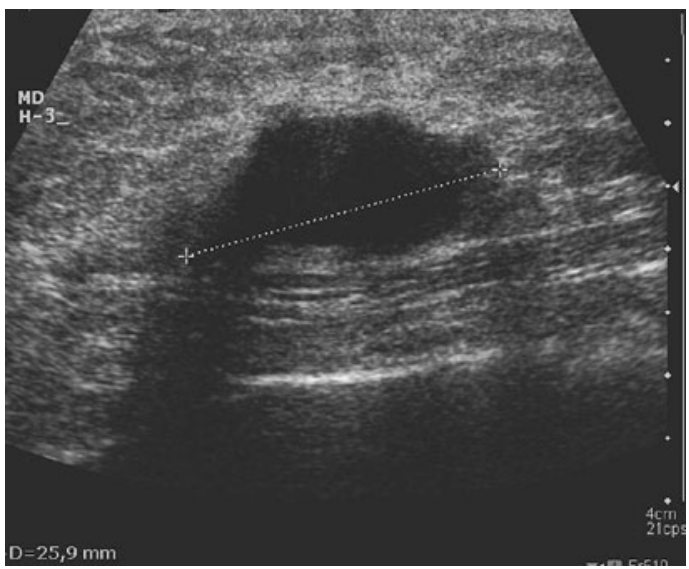

Fig. 3 Ultrasound of the lesion of the right breast 